\title{
COMPLIANCE WITH BOIL WATER ADVICE FOLLOWING A WATER CONTAMINATION INCIDENT IN THE NetherLANDS IN 2007
}

\author{
I Karagiannis ${ }^{1,2}$, B Schimmer (barbara.schimmer@rivm.nl)1, A M de Roda Husman ${ }^{1}$ \\ 1. National Institute for Public Health and the Environment (Rijksinstituut voor Volksgezondheid en Milieu, RIVM), \\ Bilthoven, the Netherlands \\ 2. European Program for Infectious Diseases Epidemiology Training (EPIET), Stockholm, Sweden
}

\begin{abstract}
In May 2007, Escherichia coli was detected in tap water supplied by a company in North Holland. The company issued advice through mass media to boil tap water before consumption; this advice was lifted six days later. A cross-sectional study was implemented to investigate compliance among residents in this area. Based on postcode, a total of 300 households, chosen randomly from a database of a private company performing internet-based surveys for different marketing purposes, were sent a self-administered questionnaire for this study. The questionnaire contained questions on demographic information, source of information regarding the advice, response to it and personal opinions on the company's reaction and the advice. Ninety-nine (66\%) households of the affected area and 90 (60\%) households from non-affected areas served by the same company replied to the survey. All respondents knew about the advice. $81.8 \%$ of the respondents in the affected area and $5.6 \%$ of the non-affected areas reported complying with the advisory. Most respondents from the affected area still used unboiled water to brush teeth, wash salads and fruits. There was no difference in compliance between men and women. Using the mass media was proved to be efficient to inform the public and could be used in the future in similar settings. However, more detailed wording of boiling advices should be considered in the future.
\end{abstract}

\section{Introduction}

Consumption of drinking water may cause waterborne disease which can be prevented by protection of the source water, efficient treatment processes and reliable distribution systems. The European Union Drinking Water Directive [1] demands monitoring of tap water for different parameters, such as Escherichia coli, to indicate possible faecal contamination from humans and animals.

System failure or human error may cause an increase in the level of pathogens in the water posing a risk of waterborne disease. For example, in 2001, a large outbreak of gastroenteritis occurred due to accidental introduction of partially treated water to the drinking water supply system in the Netherlands, resulting in 921 households being exposed to contaminated water [2].

In the event that faecal contamination is detected the drinking water company may issue an advice to boil tap water before using it for domestic purposes. On 15 May 2007, E. coli was detected in samples collected the day before of the finished tap water delivered by a company in the province Noord-Holland (North-Holland) in the Netherlands. For preventive reasons, on the same day the company issued an advice for consumers to "boil tap water for two minutes before consumption but that this was not necessary for taking a shower or washing". This information was broadcasted through mass-media including the national and regional television channel, radio and newspapers. In addition, a public website used during emergency situations (www.crisis.nl) and a toll-free telephone number were made available for the public to provide information to households in the affected area.

The boil water advice had an impact on approximately 180,000 households in the affected area comprising 13 municipalities. The advice was lifted a week later, on 22 May 2007, as risk for public health was no longer present. In September 2007, the water company published a press release informing that the cause of the water contamination was due to run-off of rainwater contaminated with faeces of breeding gulls on the roof that had seeped into one of the six storage rooms [3].

Elevated levels of microorganisms in drinking water may represent a public health risk. For this reason, we investigated compliance with boil water advice issued by the private water company following the 2007 incident.

\section{Methods}

A cross-sectional study was implemented to investigate factors that may have affected water consumption habits of the residents in the area supplied by the water company. For this purpose, on the company's behalf, a self-administered questionnaire was sent to 300 households in June 2007. Households were selected on the basis of their residence postcodes; half in the area where the advice was valid and half in areas served by the same company but where the advice did not apply. These participants were derived from a database of a private company that conducts online consumer surveys for marketing purposes.

The questionnaire contained questions on demographic information, level of urbanisation, source and time of receiving the information regarding the advice, initial and secondary response to the advice and personal opinions on the company's response and the advice itself. The data were sent back to the drinking water company and the National Institute for Public Health and the Environment, where they were analysed. The statistical analysis was done with STATA v10. 


\section{Results}

Ninety-nine households (66\%) from the area affected by water contamination and 90 households (60\%) from control areas supplied with water by the same company replied to the survey. Women more often than men responded to the questionnaire in both the affected and the non-affected areas $(57.7 \%$ of all responders). The respondents represented 189 households with a total population of 505 people, 176 (34.9\%) of whom were below the age of 18 years. There was no statistically significant difference in the number of children per household between the affected and the non-affected areas ( $p=0.112)$. Descriptive results for the two different areas are presented in Table 1.

All 189 respondents (100\%) in both areas answered that they had been informed about the advice. Ninety-five (50.3\%) of them said they had first heard about it through the television. Other sources were radio (24.3\%), friends, relatives or neighbours (22.8\%), newspapers (19.6\%) and the internet (7.4\%).

Persons living in the affected area were more frequently disappointed (14.1\%) about the choice of the company to use mass media for the advice than people residing in the nonaffected area (2.2\%). In the affected area, seven (9.3\%) of the respondents had first reacted with fear to the information on the possible contamination of water, $34(45.3 \%)$ responded with selfcontrol and 34 (45.3\%) with the intention to take measures. The corresponding percentages for the non affected area were $15.7 \%$, $72.9 \%$ and $11.4 \%$. About half $(48.5 \%)$ of the respondents from the affected area said they had looked for more information when they had heard about the advice, while the corresponding proportion of respondents from the non-affected area was only $8.9 \%(p<0.001)$. The most common source of active search for more information was the website of the water supply company.

Eighty-one (81.8\%) of all respondents in the affected area said they had complied with the advice. This was done by buying bottled water $(43.4 \%$ of all respondents in affected area) or boiling tap water for two minutes before consuming it (70.7\%). None of the respondents in the area stopped consuming tap water completely. Five $(5.6 \%)$ of the respondents in the non-affected area were buying bottled water and three of them $(3.3 \%)$ were boiling tap water during the advice. These numbers were considerably lower than the corresponding ones in the affected area, but showed that compliance exceeded beyond the affected area.

Even though it had not been advised to boil water for activities such as washing and showering, 26 (26.3\%) of the respondents in the affected area stated that they had not been aware of that.

Concerning the image of the drinking water company, 177 respondents $(93.7 \%)$ thought that the company had done well informing the consumers about the water contamination and its response to it. This prevailing opinion was not different between respondents from the affected area and those from the non affected area.

The respondents' compliance with the advice was independent of sex, age and the presence of children in the household. However, the respondents were 138.6 times more likely to follow the advice if a second person in the household was following it as well $(p<0.001)$.

Reasons for non-compliance with the advice are given in Table 2.
Some of the respondents replied that they had been using boiled water for uses other than drinking, too. These results are shown in Table 3.

The majority of the respondents stated that their image of the company had not changed after the incident and the six-day advice (78.8\% in the affected area and $88.9 \%$ in the non-affected area).

\section{Factors affecting compliance}

The type of mass media from which people in the affected area found out about the advice played no significant role in the subsequent compliance of the respondents. The highest compliance rates occurred among those in the affected area who heard about the advice from the internet $(90 \%)$ or from friends $(89.5 \%)$. Respondents informed by more than one source were more likely

T A B L E 1

Survey on boil water advice in the North Holland province in the Netherlands, 2007, demographic characteristics of the respondents

\begin{tabular}{|l|c|c|c|c|}
\hline & $\begin{array}{c}\text { Affected area } \\
\text { (n=99) }\end{array}$ & $\begin{array}{c}\text { Non- affected area } \\
(\mathbf{n}=90)\end{array}$ & $\begin{array}{c}\text { Total } \\
(\mathbf{n}=189)\end{array}$ & $\boldsymbol{p}$-value \\
\hline $\begin{array}{l}\text { Respondent's age } \\
\text { (years) }\end{array}$ & 47.7 & 48.4 & 48.0 & 0.7549 \\
\hline $\begin{array}{l}\text { Number of people } \\
\text { living in the household }\end{array}$ & 2.62 & 2.82 & 2.72 & 0.2526 \\
\hline $\begin{array}{l}\text { Number of children } \\
\text { living in the household }\end{array}$ & 0.78 & 1.11 & 0.93 & 0.0510 \\
\hline
\end{tabular}

T A B L E 2

Reasons for non-compliance with boil water advice in the affected area in the North Holland province, the Netherlands, $2007(n=11)$

\begin{tabular}{|l|c|c|}
\hline Reason given & N & $\%$ \\
\hline I have enough immunity & 1 & 9.1 \\
\hline The risk was small & 1 & 9.1 \\
\hline I was not worried & 3 & 27.3 \\
\hline It was too much inconvenience & 2 & 18.2 \\
\hline I forgot about it & 2 & 18.2 \\
\hline I had only just found out & 2 & 18.2 \\
\hline Total & 11 & 100.0 \\
\hline
\end{tabular}

\section{T A B L E 3}

Use of boiled water for uses other than drinking in the affected area in the North Holland province, the Netherlands, $2007(n=99)$

\begin{tabular}{|l|c|c|}
\hline Domestic use & N & $\%$ \\
\hline To brush teeth & 30 & 28.1 \\
\hline To wash salads & 48 & 35.6 \\
\hline To wash fruits & 51 & 48.4 \\
\hline To make coffee & 56 & 54.7 \\
\hline To make ice cubes & 89 & 87.2 \\
\hline To give to pets & 73 & 69.4 \\
\hline
\end{tabular}


to have complied with the advice (90.9\% against $79.2 \%$ ) but this difference was not statistically significant. The source of information did not depend on the age $(p=0.6532)$. Compliance with the advice did not differ between households with children and those without children $(p=0.536)$.

Respondents who undertook active search for more information may have been more likely to follow the advice than those who did not proceed to further active search for more information $(89.4 \%$ vs. $74.5 \%, p=0.058$ )

Since all respondents knew about the advice, it was not possible to estimate unwitting compliance rates.

\section{Conclusions}

Since excess of standard levels of certain microorganisms such as $E$. coli indicate faecal contamination and the possible presence of pathogens in tap water, the time between the water sampling, water analysis and the boil water notice is essential. During this period, consumers may be exposed to tap water of unacceptable quality. The choice of mass media for broadcasting the advice is therefore believed to be an effective measure to prevent panic and to protect public health.

From this study, it can be concluded that participating consumers not only thought that they had been informed about the advice in a timely manner, but that also the response of the company to ensure the advice would reach the public had been satisfactory as well as the choice of communication channels. Thus, the incident did not lead to customers' dissatisfaction or a degradation of the company's image.

The sample in our study derived from a database of people who subscribed to be included in different research surveys. This could raise questions regarding the representativeness of the study population. We agree that there is a need for similar studies with samples deriving randomly from the whole population and not from potentially biased data sources. For example, $100 \%$ of the participants stated that they had been informed about the boiling water advice; however, subscribers to online databases for marketing purposes may be more likely to regularly follow the news than the general population.

In the Netherlands, boil water notices are not harmonised but are determined by the drinking water company itself. This results in different advice with respect to, for instance, boiling time. Internationally recognised guidelines, such as the World Health Organization (WHO) Guidelines for Drinking Water Quality [4], could be taken into consideration in case of similar "crises" in the future. According to data from the water company involved in our study, about thirty boil water advices are issued per year in their responsibility area (ca. 700,000 households); involving on average 100 households per time. So, the chance to receive a boil water advice is small but existing.

The inclusion of recommendations including use of water for brushing teeth, washing fruits and vegetables may also prove helpful in future advice, since it is not only consumption of water through drinking that may pose a risk to the consumer. Bathing and showering may also need to be addressed separately, as a possible link between this kind of exposure to contaminated water and itching has been described elsewhere [2]. Also, although this conclusion does not directly follow from our results, vulnerable groups should be targeted separately in the advice; elderly people and children may easily miss information disseminated through the means of mass media $[5,6]$.

Few studies have been published on boil water notices and their results seldom reach the public. Further research would also be useful to incorporate findings from compliance studies to model health effects of drinking contaminated water during similar events.

\section{References}

1. Council Directive 98/83/EC of 3 November 1998 on the quality of water intended for human consumption, Official Journal of the European Communities. 1998;L330:32-54. Available from: http://eur-lex.europa.eu/LexUriServ/ LexUriServ.do?uri=0J:L:1998:330:0032:0054:EN:PDF

2. Fernandes TM, Schout C, De Roda Husman AM, Eilander A, Vennema H, van Duynhoven YT. Gastroenteritis associated with accidental contamination of drinking water with partially treated water. Epidemiol Infect. 2007;135(5):81826.

3. PWN Waterleidingbedrijf Noord-Holland [PWN water service North Holland]. Oorzaak E. Colibesmetting Hoofddorp gevonden [Cause of E. coli contamination in Hoofddorp found]. Press release, 13 September 2007 [in Dutch]. Available from: https://www.pwn.nl/SiteCollectionDocuments/Persdossiers/Oorzaak_ EColi_13092007.pdf

4. World Health Organization. Guidelines for drinking-water quality, third edition incorporating first addendum. Vol 1. Recommendations. Geneva: World Health Organization; 2006. Available from: http://www.who.int/water_sanitation_ health/dwq/gdwq3rev/en/

5. O'Donnell M, Platt C, Aston R. Effect of a boil water notice on behaviour in the management of a water contamination incident. Commun Dis Public Health. 2000;3(1):56-9.

6. Hulkko T, Kuusi M, Virtanen M, Laine J, Lyytikåinen. Communication in Nokia during waterborne gastroenteritis outbreak. Poster abstract reference: 20080057. ESCAIDE conference, Berlin; 2008. Available from: http://www.escaide. $\mathrm{eul}$

This article was published on 26 March 2009.

Citation style for this article: Karagiannis I, Schimmer B, de Roda Husman AM. Compliance with boil water advice following a water contamination incident in the Netherlands in 2007. Euro Surveill. 2009:14(12):pii=19156. Available online: http://www. eurosurveillance.org/ViewArticle.aspx?ArticleId=19156 